Dear Author,

Please, note that changes made to the HTML content will be added to the article before publication, but are not reflected in this PDF.

Note also that this file should not be used for submitting corrections. 


\title{
Sustainable Energy Security for India: An assessment of energy demand sub-system
}

\author{
Kapil Narula ${ }^{\mathrm{a}, \mathrm{b}, *}$, B. Sudhakara Reddy ${ }^{\mathrm{b}}$, Shonali Pachauri ${ }^{\mathrm{c}}$ \\ a National Maritime Foundation, Varuna Complex, Airport Road, NH - 8, New Delhi, India \\ ${ }^{\mathrm{b}}$ Indira Gandhi Institute of Development Research, Gen. A.K. Vaidya Marg, Goregaon (E), Mumbai, India \\ ' International Institute for Applied Systems Analysis, Laxenburg, Austria
}

\section{H I G H L I G H T S}

- A multidimensional Sustainable Energy Security (SES) index is developed.

- The SES index evaluates the performance of the energy demand sub-system using 23 metrics.

- Dimensional indices are calculated for 2002, 2007 and 2012 for various sectors for India.

- The aggregate demand sub-system SES index shows an increase by 10\% from 2002 to 2012.

- The index is $30 \%$ short of the target implying a large scope for improvement.

\section{A R T I C L E I N F O}

\section{Article history:}

Received 8 September 2015

Received in revised form 10 February 2016

Accepted 29 February 2016

Available online $\mathrm{xxxx}$

\section{Keywords:}

Energy assessment modeling

Energy security

Energy sustainability

Urban residential sector

Multidimensional energy index

\begin{abstract}
A B S T R A C T
This paper presents a quantitative assessment of Sustainable Energy Security (SES) of the energy demand sub-system for India by calculating a multidimensional SES index. The demand sub-system has been evaluated for four dimensions of SES, viz., Availability, Affordability, Efficiency and (Environmental) Acceptability using 23 selected metrics. A hierarchical structure has been used to construct indices using 'scores' (objective values of selected metrics), and 'weights' (subjective values, representing importance of each metric) which are then aggregated, to obtain a SES index. Various sectors of the energy demand sub-system are evaluated and dimensional and sectoral indices are calculated for the years 2002, 2007 and 2012. Assessment of the obtained energy indices is undertaken (separately for rural and urban residential sector) and results reveal that all (except one) sectoral indices have shown an increase during the period of assessment. The results show that from 2002 to 2012, the aggregate SES index has increased by approximately $10 \%$ which indicates a gradual improvement in the sustainability and security of the energy demand sub-system. However, the SES index is approximately 0.7 (against a desired target of 1.0), which implies that there is still a large scope for improvement in the performance of the India's energy demand sub-system. A sensitivity analysis of various indices reveals that the SES index is relatively robust to variation in weights allotted to different dimensions and hence provides a reliable assessment of the energy demand sub-system.
\end{abstract}

(ㄷ) 2016 Published by Elsevier Ltd.

\section{Introduction}

Sustainable Energy Security (SES) has been defined as "provisioning of uninterrupted energy services in an affordable, equitable, efficient and environmentally benign manner" and is proposed as an end goal of the energy policy for a developing country [1]. Energy security is a property of the energy system [2] and a

\footnotetext{
* Corresponding author at: National Maritime Foundation, Varuna Complex, Airport Road, NH - 8, New Delhi, India.

E-mail address: kapiln@igidr.ac.in (K. Narula).
}

structured analysis has been proposed by Hughes [3] and a SES index for developing countries has been developed by Narula and Reddy [4].

The physical energy system of a country can be divided into three distinct sub-systems, 'energy supply' sub-system, 'energy conversion \& distribution' sub-system and 'energy demand' subsystem. The energy supply sub-system includes domestic extraction of primary energy and energy imports in the form of coal, crude oil, natural gas etc. Primary energy is then converted to different forms of energy carriers such as electricity and oil products which is distributed to the end users and this forms a part of the 
energy conversion \& distribution sub-system. The energy demand sub-system consists of various sectors of the economy such as industrial, residential, and transport and final energy is consumed in various sectors.

The demand of energy services from various sectors of the economy triggers the supply of energy in an energy system. The energy supply sub-system responds to this demand and fulfils it to the extent feasible. Hence the demand sub-system is the driver and is critical for attaining SES for a country. The importance of the demand sub-system is also evident in India's approach to energy security, which is summarized as "The country is energy secure when we can supply lifeline energy to all our citizens as well as meet their effective demand for safe and convenient energy to satisfy various needs at affordable costs at all times with a prescribed confidence level considering shocks and disruptions that can be reasonably expected" [5]. However, the concept of SES goes beyond providing 'lifeline' of energy and beyond 'citizens' to include all sectors of the economy.

While increase in per capita energy consumption is inevitable and even desirable, it can be reduced as compared to the Business As Usual (BAU) scenario by adopting Demand Side Management (DSM) programs, and by reducing wastage (such as by utilizing waste heat). In case of electricity, peak demand management and dynamic demand reduction do not contribute directly to reduction in aggregate energy consumption, but it avoids the setting up of ture, thereby contributing to SES.

There are a large number of indices in literature, for evaluating energy security and sustainability. Narula and Reddy [6] have evaluated three indices, 'Energy Sustainability Index', 'International Index of Energy Security Risk' and 'Energy Architecture Performance Index', in detail and have concluded that these indices do not give reliable information for developing countries and further work is required for assessing the energy system of these countries. Coude [7] provides a good starting point for a literature review on energy security. Most of the studies on energy security such as Gupta [8], Cabalu [9], Cohen et al. [10], Le Coq and Paltseva [11] are limited to security of energy supply and deal with mostly oil and gas, while neglecting the demand side of the energy system. Although Jewell [12] extends its assessment to other energy sources using the Model of Short-term Energy Security (MOSES), it falls short of undertaking a detailed assessment of the energy demand sub-system. Hence the most prevalent view of energy security is from the supply side perspective as studies often overlook the assessment of the demand sub-system while evaluating the country's energy security and sustainability.

More recently, energy security for Singapore was evaluated using a framework with 22 indicators, three sub-indexes and a composite index. This assessment helped in quick identification of deficiencies within the Singapore's energy supply chain and pinpointed the main weaknesses in the energy system [13]. Energy security assessment for Thailand was also undertaken using energy security indicators and the paper recommended that Thailand needs to develop specific policy measures to enhance energy security by paying attention to energy markets, national energy efficiency and lower $\mathrm{CO}_{2}$ emissions [14]. Energy security for the Association of Southeast Asian Nations (ASEAN) was analysed using the 4-A's framework and the importance of energy efficient technologies for achieving energy security and sustainable energy policy goals were highlighted [15]. A broader approach using a complex systems perspective in conceptualizing the energy system and a policy-oriented approach for identifying risks, threats and vulnerabilities for assessment of energy security was also undertaken [16]. While there are different approaches to analyse the energy system, this paper focuses on comprehensively and additional conversion, transmission and distribution infrastruc- systematically assessing the performance of the demand subsystem, thereby highlighting its role towards attaining SES for India.

The aim of this paper is to assess the SES for the energy demand sub-system for India. The paper presents the methodology for calculating the SES index in the next section briefly. Scoring matrices are derived for various sectors and scores are calculated in Section 3 followed by calculation of weighting matrices. Results are presented in Section 4, followed by a discussion on sensitivity of the derived SES index for the demand sub-system, prior to concluding the paper.

\section{Material and methodology}

The framework for assessment and the methodology to calculate the SES index is presented briefly in this section.

The hierarchical structure for the aggregation of SES index for an energy system of a country is shown in Fig. 1. The SES of an energy system is a function of the SES of the three sub-systems: supply, conversion \& distribution and demand. Each sub-system has various components. The energy supply sub-system is assessed for eight primary energy sources: coal, oil, natural gas, biomass, nuclear, wind, solar and hydro. The energy conversion \& distribution sub-system is assessed for five energy carriers: coal, gas, oil products, biomass and electricity and the energy demand subsystem is assessed for five main sectors of the economy: Residential, Industrial, Commercial (Services), Agriculture and Transport. These components are further divided into sub-components for a detailed assessment. SES of domestic and imported energy for various energy sources are assessed separately in the energy supply sub-system and SES of rural and urban consumers are assessed in detail for the residential sector in the demand sub-system. The structure for assessment of SES is similar to the S/D (Supply/ Demand) index proposed by Scheepers et al. [17,18], but differs in many details. This hierarchical structure allows us to undertake a complete assessment of the SES of an energy system for a country or a region.

SES is a multidimensional concept and there are various dimensions and indicators which can be chosen to assess the energy system. Four different dimensions-Availability (related to adequacy and access), Affordability (related to prices and consumer's ability to pay for energy), Environmental Acceptability (related to resource extraction and waste production) and Efficiency (related to energy productivity) are selected for undertaking an assessment of SES of an energy system. These dimensions are distinct and selected indicators can be grouped under respective dimensions for assessing the SES. The dimensions are further divided into various categories and sub-categories which help in easy comprehension.

\subsection{Constructing a SES index}

In this paper, measurement of SES is undertaken through the use of 'indicators'. Quantitative indicators are based on data and can be used for measurement without any subjectivity and are known as 'metrics'. Following the hierarchical structure for assessment of SES for an energy system, a hierarchy of energy indices can be evolved using a combination of 'weights' and 'scores' and a composite SES index can be aggregated. Working level details are given in the following sub-sections but more details on the methodology can be found in [4].

\subsection{Hierarchical structure for assessment of energy system}




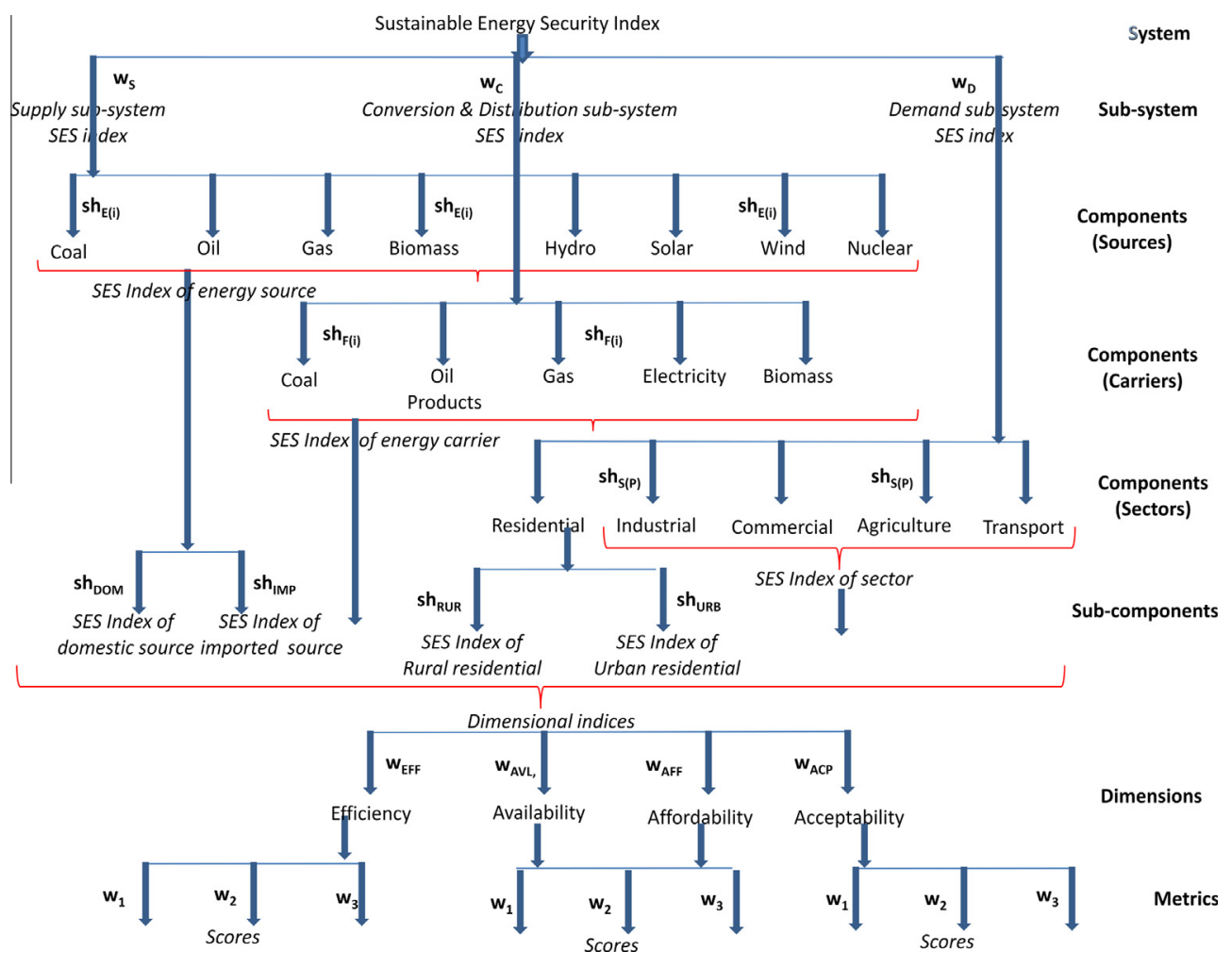

Fig. 1. Hierarchical structure for aggregation of SES index for an energy system.

\subsection{Model for constructing an index}

The model for creating an SES index consists of a scoring matrix and a weighting matrix, which are multiplied together to form a vector, elements of which can be considered as an 'index'. 'Scores' are elements of the scoring matrix and these are objective values which are obtained from statistical data and scoring rules for various metrics. On the other hand, 'weights' represent the subjective component and can be interpreted as a measure of relative importance of the metric. This model has been used to construct a SES index for undertaking a comparative assessment of energy sources [19].

\subsubsection{Scoring matrix}

A scoring matrix consists of ' $n$ ' rows, for different components, to be evaluated and ' $m$ ' columns, having different metrics, $I_{j}$. Each element of the matrix has the 'score', $s\left(E_{i}, I_{j}\right)$, which represents the value of the indicator $I_{j}$ for a particular energy source $E_{i}$. The elements of the $(n \times m)$ scoring matrix are filled using these scores which are derived from a combination of the value of the metric and the scoring rule. The weighting matrix is a column matrix, having ' $m$ ' rows and each element is assigned the values $w_{j}$. Each element of the vector, obtained by the multiplication of the scoring and the weighting matrix, is the index corresponding to the particular energy source $E_{i}$. Metrics are collated from various data sources (if directly available), or are calculated from its components. Data imputation and other approximations may have to be undertaken to account for the missing data in certain cases.

\subsubsection{Scoring rules}

The 'distance to reference' approach is used to derive the scores for the selected metrics of the demand sub-system. The 'score' can be calculated using the generic Eq. (1).

$$
n=\frac{\operatorname{value}(x)-f * \operatorname{target}(x)}{f^{\prime} * \operatorname{target}(x)}
$$

where

value $(x)=$ actual value of the selected metric; target $(x)=$ Desired value of the metric;

$f=$ allotted value $(1 / 5)$

$f^{\prime}=(1-f)=4 / 5$

The choice of the value of ' $f$ ' is left to the user and a value of $(1 / 5)$ is allotted. This may be considered as a variable and an analysis of the sensitivity of the result of the index to the chosen value of this variable is undertaken later in this paper. The appropriate target for each metric is decided based on a pragmatic judgment and are explained in detail.

There are two types of metrics: one for which a higher value is desirable (e.g. percentage of population with access to electricity) and the other, for which a lower value result in higher SES (e.g. sectoral energy intensity). The scoring rules for these metrics are different and the scores are derived using Eq. (1) and are presented in Eqs. (2) and (3).

(a) For metrics where lower values are desirable

$$
\begin{aligned}
& \text { If value }(x) \leqslant \text { target }(x): \text { Score }=1 \\
& \text { If } 5 * \text { target }(x)>\text { value }(x)>\operatorname{target}(x): \text { Score } \\
& =\left(\frac{(5 * \text { target }-x)}{4 * \text { target }}\right)
\end{aligned}
$$

If value $(x) \geqslant 5 * \operatorname{target}(x):$ Score $=0$

(b) For metrics where higher values are desirable 
If value $(x) \geqslant \operatorname{target}(x):$ Score $=1$

If $0.2 *$ target $(x)<$ value $(x)<$ target $(x)$ : Score $=\left(\frac{x-(\text { target } / 5)}{\left(\frac{4}{5}\right) * \text { target }}\right)$

If value $(x) \leqslant 0.2 *$ target $(x):$ Score $=0$

\subsection{Energy indices for demand sub-system}

As shown in Fig. 1, the assessment of the demand sub-system can be undertaken by calculating the energy indices for five main sectors of the economy. The residential sector is further subdivided into rural and urban sub-components. Scores obtained by various metrics are evaluated and weights are allotted based on a survey. The share of final energy consumed by various sectors, $\mathrm{sh}_{\mathrm{S}(\mathrm{p})}$, is used as weights for various components and the share of rural and urban population, $s h_{\mathrm{RUR}}, \mathrm{sh}_{\mathrm{URB}}$, is used as weights for the sub-components of the residential sector. Scores obtained by various metrics when multiplied by corresponding weights give dimensional indices and when these are multiplied by dimensional weights, they result in the SES index for the sector. Various energy indices can therefore be calculated and aggregated, bottom-up, to arrive at the demand sub-system energy index.

\subsection{Selected metrics and targets}

Different metrics are chosen to represent different dimensions of SES. The selected metrics, grouped under categories, subcategories and dimensions along with the variables and units for the demand sub-system are given at Appendix A.

One of the key issues is the selection of targets or desirable values. There are declared 'global targets' such as doubling the global rate of improvement in energy efficiency by 2030, adopted by Sustainable Energy for All (SE4ALL) initiative [20]; 'regional targets' such as EU wide headline targets of $20 \%$ improvement in energy efficiency by 2020 (these have been further disaggregated into country wide indicative targets of absolute levels of primary and final energy consumption in 2020 for EU countries) [21]; and 'country targets' such as those announced by China ( $16 \%$ reduction in the overall energy intensity, as a goal of its 12 th five year plan from 2011 to 2015) [22]. In case of India, there are no country wide goals for reduction of energy intensity. However, for emission intensity, India has voluntarily agreed to adopt the Copenhagen Accord target of reduction of the overall $\mathrm{CO}_{2}$ emission intensity by $25 \%$, relative to 2005 levels, by 2020 [23]. Under these circumstances where targets have not been defined by the governments, this paper selects appropriate targets for benchmarking with appropriate justification. It is to be noted that selection of targets has some subjectivity and can be questioned. However, the rationale for selection of the target is clearly explained. Notwithstanding the chosen values, different targets can be selected by other users and an index can be calculated by applying this framework.

\section{Calculation of scoring matrix}

The scoring matrices for five sectors are derived in this section. Scores are calculated from the raw value of the selected metric and the scoring rules.

\subsection{Residential sector}

Energy is used in the residential sector primarily for meeting cooking and lighting services. De la Rue du Can et al. [24] estimated that approximately $420 \mathrm{~kW} \mathrm{h/household/yr} \mathrm{was} \mathrm{used} \mathrm{in} 2000$ by an average Indian household ( $908 \mathrm{~kW} \mathrm{h/household/yr} \mathrm{for} \mathrm{urban;}$ $224 \mathrm{~kW}$ h/household/yr for rural areas). The study also estimated that the average urban Indian household will consume $2972 \mathrm{~kW} \mathrm{h/household/yr} \mathrm{(approximately} 595 \mathrm{~kW} \mathrm{h/cap/yr),} \mathrm{while}$ the consumption in rural household will rise to $1311 \mathrm{~kW} \mathrm{~h}$ /household/yr (approximately $262 \mathrm{~kW} \mathrm{h/cap/yr)} \mathrm{in} \mathrm{2020.} \mathrm{As} \mathrm{electricity}$ consumption differs widely, different target values are taken for rural and urban areas for this paper. A target of $600 \mathrm{~kW} \mathrm{h/capita/}$ $\mathrm{yr}$ and $260 \mathrm{~kW} \mathrm{h/capita/yr} \mathrm{has} \mathrm{been} \mathrm{selected} \mathrm{for} \mathrm{the} \mathrm{Indian} \mathrm{urban}$ and rural household, respectively. While there are higher forecasts of electricity consumption by other studies $(731 \mathrm{~kW} \mathrm{~h} / \mathrm{cap} / \mathrm{yr}$ was estimated for 2030 by a detailed bottom up analysis undertaken by World Bank [25]), it is assumed that the selected target would be sufficient to meet the requirement of various energy services in households.

Cooking needs are met by different fuels which are used in varying quantities amongst rural and urban households. It is widely accepted that LPG is a clean and convenient fuel for cooking. D'Sa and Murthy [26] reported that the average annual use of LPG per connection (per household) across India was approximately $115 \mathrm{~kg}$ for the year 2003. The size of the Indian household is decreasing and reduced from 5.3 persons per household to 4.8 persons per household according to the Census of India. With 4.8 persons per household, a target of $24 \mathrm{~kg} /$ capita/yr is adopted for the metric R2 (Average per capita LPG consumption per year).

'Energy Access' is measured by two metrics, '\% of population with access to electricity' (R3) and '\% of population using LPG for cooking' (R4). The target value for both R3 and R4 is 100\% implying that all households in rural as well as urban India should be able to use electricity for lighting and LPG for cooking.

Affordability of energy can be measured by the ability of a household to pay for energy. 'Percentage of expenditure on fuel and light by households' (R5) is chosen as a metric to measure the paying ability of the household. While this value varies across income deciles and rural/urban households, the average value of $\mathrm{R} 5$ is in the range of $6.5-10.5 \%$ for the past 25 years for India [1]. A target value of $7 \%$ is taken as the average value for R5 for rural as well as urban areas. A lower value of R5 is desirable as it contributes to greater affordability and increases SES.

Price distortion due to subsidies is measured separately for cooking and lighting (metric R6 and R7). The Price Distortion Score (PDS) is calculated by accounting for fiscal subsidies as well as 'under recoveries' to the Oil Marketing Companies (OMCs) for LPG and kerosene. OMC's in India are often forced by the government to sell oil products below their trade parity price for making them affordable. This price gap between selling price and the trade parity price is a notional loss to the OMCs and is termed as 'under recoveries'. The actual price is arrived at by adding the subsidy to the retail (sale) price on per unit basis. The PDS is in the range of $0-1$, where 0 represents $0 \%$ subsidy i.e. retail price is same as actual price and 1 represents $100 \%$ subsidy (energy is provided free of cost). The weighted sum of PDS (WSPDS) for cooking is then used to calculate R6. The value of R6 is 1 when there is no subsidy for any type of fuel used for cooking and will be between 0 and 1 for all other cases.

Similarly, the 'weighted sum of price distortion score for lighting' (R7) is calculated. There are two main sources of lighting: kerosene and electricity, both of which are subsidized. The PDS value for kerosene used in lighting is obtained as above accounting for subsidies on a per unit basis for kerosene. In the case of electricity, the (all India) average generation cost for electricity is used as the 'actual price' and the average electricity tariff for the sector is used as the 'retail price'. The price of electricity is different for different sectors as electricity is cross-subsidized in India. The range of PDS for electricity is between -1 and 0 for industrial and commercial consumers as the retail price of electricity is higher than the actual 
price and is between 0 and 1 , for residential and agricultural consumers, as the electricity is subsidized for these sectors. The weighted sum of PDS (WSPDS) for lighting and value of R7 is calculated as shown in Appendix A. The target value for both R6 and R7 is taken as 1 , which implies no distortion in price due to subsidies. A higher value (close to 1 ), would help in increasing the SES of a country.

India had voluntarily agreed to cut its carbon intensity by $25 \%$ below 2005 levels by 2020 in the run up to Copenhagen meet in 2009. If this commitment is applied uniformly across all sectors, the value for metric R8 would be 0.255 tons $\mathrm{CO}_{2}$ per household per year (the value of metric R8 for 2005 was 0.34 tons $\mathrm{CO}_{2}$ per household) and this is selected as the target.

Three metrics are selected to represent the 'Efficiency' dimension for the residential sector. R9 can be written in an expanded form as Eq. (4).

$\mathrm{R} 9=\mathrm{sh}_{\text {Electricity }, \mathrm{L}} \times(\text { Average Efficacy })_{\text {bulb }}+\mathrm{sh}_{\text {Kerosene } \mathrm{L}}$

$$
\times(\text { Average Efficacy })_{\text {Kerosene lamp }}
$$

There are different kinds of end use devices for converting electricity to light such as incandescent bulbs, Compact Florescent Lamps (CFL) and LED bulbs and kerosene lamps are also used for lighting. Efficacy, which is the ratio of power input to light output i.e. emitted flux (lumens) divided by power drawn (watts) is the right unit to measure lighting efficiency. The efficacy of an incandescent bulb of $60-100 \mathrm{~W}$ is $14.5-17.5$ lumen/watt while a LED bulb has an efficacy of 40-100 lumen/watt. A value of 15 lumen/ watt is used as the average efficacy for lighting provided by electric bulb and the average efficacy of a kerosene lamp is taken as 0.15 lumen/watt. It is desirable that all residential consumers shift to electricity as the primary energy source for lighting and a target of 30 lumen/watt is taken as the desirable value for R9.

For calculating the value of the metric R10, the average efficiency of different cook stoves using fuel $F(i)$ is multiplied by the share of type of fuel used for cooking. The average efficiency of an LPG stove is 60\% and it is selected as the target for R10.

R11 can be calculated using the Appliance Efficiency Score (AES). Four main types of appliances are taken for analysis in the residential sector: TV, Refrigerator, Fan and air conditioner. Air coolers, water heaters and other appliances such as microwave ovens and computers contribute to a small share of electricity consumed and are hence not included in the analysis. AES is calculated using the Eqs. (2) and (3) which were used earlier to calculate the scoring rules, where value $(x)$ is the efficiency level of the appliance (different appliances have different units for measuring efficiency) and target $(x)$ is the efficiency level. The target levels for different appliances which are adopted from the Super Efficient Appliances (SEA) program are as follows [27].
(a) TV: 36 watts;
(b) Refrigerator: $128 \mathrm{~kW} \mathrm{h/yr;}$
(c) Fan: 35 watts and
(d) Air Conditioner: 4.9 Energy Efficiency Ratio (EER).

A higher value for EER for AC indicates higher efficiency and is desirable and a lower value is desirable for all other appliances. The obtained values of AES will be in the range of (0-1) and when multiplied by the share of appliances, it will give a weighted sum of AES, or the average appliance efficiency (R11). The target value of AES has been selected as 1 , which implies that the most energy efficient (technically feasible) appliances are used.

\subsection{Industrial sector}

The value of the metric I1 (Number of hours of electricity in a day) varies across different states of India. As reliable data is not available, this value is estimated using data from case studies. The target for I1 is $24 \mathrm{~h}$ which implies that electricity should be available for $24 \mathrm{~h}$ in a day. Metric I2 is calculated for the sector in a similar manner as that of the residential sector. The target value for $\mathrm{I} 2$ is 1 , which implies that there should be no distortion in energy prices due to subsidies. A high value of I2 (closer to 1) is desirable for attaining SES. India's $\mathrm{CO}_{2}$ emission intensity for the industrial sector is higher than the world average which implies that there is a scope for decarbonisation of the sector which is heavily dependent on coal. If the $25 \%$ reduction in emission intensity (from 2005 levels) is applied to this sector, it implies a target value of $0.32 \mathrm{kgCO}_{2} / \$ 05_{\mathrm{p}}$ (value of I3 in 2005 was $0.43 \mathrm{kgCO}_{2} / \$ 05_{\mathrm{p}}$ ) (where $\$ 05_{\mathrm{p}}$ refers to dollars at constant exchange rate, price and purchasing power parities of the year 2005). However a target of $0.12 \mathrm{kgCO}_{2} / \$ 05_{\mathrm{p}}$ is selected which represents a reduction of approximately $75 \%$, from the current levels. Considering that the emission intensity of Hungary and Philippines was $0.12 \mathrm{kgCO}_{2} / \$ 05_{\mathrm{p}}$ in 2011 , such a target is considered achievable. It is to be noted that there are other developing countries like Paraguay and Sri Lanka which have even lower emission intensity of $0.03 \mathrm{kgCO}_{2} / \$ 05_{\mathrm{p}}$ and $0.05 \mathrm{kgCO}_{2} / \$ 05_{\mathrm{p}}$ respectively. India's energy intensity for the industrial sector $(0.17 \mathrm{kgoe} / \$ 05 \mathrm{p})$ is higher than the world's average $(0.14 \mathrm{kgoe} / \$ 05 \mathrm{p})$. The selected target for metric I4 is $0.05 \mathrm{kgoe} / \$ 05_{\mathrm{p}}$ which is also the value for Switzerland (2011) and Hong Kong (2011). It may be useful to look upon it as the ultimate target in the long run and efforts must be made to achieve this target by adoption of aggressive energy efficient practices in the Indian industry.

\subsection{Services sector}

Metric S1 is similar to metric I1 and this value is estimated as exact data is unavailable. The adopted target for S1 is $24 \mathrm{~h}$ and a higher value of S1 is desirable. S2 is calculated in a manner similar to the residential sector and its target is 1 , which implies that there should be no distortion in prices of fuel due to subsidies. India's $\mathrm{CO}_{2}$ intensity for the services sector is lower than the world average as the services sector is highly productive. Further, it continues to show a declining trend implying that further improvements are possible. The value for metric S3 in 2005 was $0.011 \mathrm{kgCO}_{2} / \$ 05_{\mathrm{p}}$. A $25 \%$ reduction in this value implies a target value of $0.008 \mathrm{kgCO}_{2} /$ $\$ 05_{\mathrm{p}}$. However a target of $0.005 \mathrm{kgCO}_{2} / \$ 05_{\mathrm{p}}$ is selected for $\mathrm{S} 3$. This target represents a reduction of approximately 55\% from 2011 levels and is considered achievable, considering that the emission intensity of one of the best performing country was $0.002 \mathrm{kgCO}_{2} /$ $\$ 05_{p}$ (Brazil, 2011). India's energy intensity for the services sector is approximately half as that of the world average, which indicates that the sector uses energy very efficiently. The selected target for metric S4 is $0.006 \mathrm{kgoe} / \$ 05_{\mathrm{p}}$ (where kgoe refers to $\mathrm{kg}$ of oil equivalent) which represent a 45\% reduction from 2011 levels. Mexico, which is a country in a similar development stage, had the same value in 2011.

\subsection{Agriculture sector}

Energy is primarily used in the agricultural sector for pumping water and tilling land. For attaining SES for the sector, the energy demand for pumping applications should be preferably met by electricity. The target value selected for A1 is $100 \%$ which implies that it is desirable that all pump sets are electrified. A2 is calculated for the sector in a similar manner as that of the residential sector. Based on a similar reasoning, its target value is 1 and a high value of $\mathrm{A} 2$ is desirable for attaining SES. India's $\mathrm{CO}_{2}$ intensity for the agricultural sector is much lower than the world average and the country already ranks in top five countries of the world. As further large reductions in the sector are not possible, a target value of 
$0.011 \mathrm{kgCO}_{2} / \$ 05_{\mathrm{p}}$ is taken for metric $\mathrm{A} 3$. This was also the value of A3 for India in 1990. India's energy intensity for the agriculture sector is approximately half $\left(0.018 \mathrm{kgoe} / \$ 05_{\mathrm{p}}\right)$ as that of the world average $\left(0.043 \mathrm{kgoe} / \$ 05_{\mathrm{p}}\right)$. The selected target for metric A4 is $0.010 \mathrm{kgoe} / \$ 05_{\mathrm{p}}$ which is also the value for Philippines in 2011 and close to that of Pakistan $\left(0.008 \mathrm{kgoe} / \$ 05_{\mathrm{p}}\right.$ in 2011$)$. Both countries have similar agricultural practices and the reduction in energy intensity to achieve the target is approximately $45 \%$, which is a reasonable target.

\subsection{Transport sector}

A low value of T1 (percentage share of fossil fuel used for transportation) is desirable as it indicates that other energy sources are also used in the sector. European Union has a target of reducing the percentage share of liquid fuel in transport sector to $90 \%$ by 2020 and this is the selected target value for T1. T2 is calculated for the sector in a similar manner as for other sectors and its target value is 1 . A high value of T2 is desirable for attaining SES. India's $\mathrm{CO}_{2}$ intensity for the transport sector is approximately half of the world average and the country ranks in top ten countries of the world. While a reduction of emission intensity by $25 \%$, will lead to a target of $0.03 \mathrm{kgCO}_{2} / \$ 05_{\mathrm{p}}$, (T3 was $0.04 \mathrm{kgCO}_{2} / \$ 05_{\mathrm{p}}$ for India in 2005), India can be ambitious and can adopt a target of $0.02 \mathrm{kgCO}_{2} / \$ 05_{\mathrm{p}}$ which is the lowest emission intensity for the transport sector and is exhibited by Hong Kong. India's energy intensity for the transport sector which was $0.015 \mathrm{kgoe} / \$ 05_{\mathrm{p}}$ in 2012 is less than half as that of the world average which stood at $0.034 \mathrm{kgoe} / \$ 05_{\mathrm{p}}$ in 2012 . The selected target for metric T4 is $0.014 \mathrm{kgoe} / \$ 05_{\mathrm{p}}$. This value is chosen as it is forecasted that demand for motorized transport will grow in India due to large scale urbanization and the value of T4 is likely to increase.

\subsection{Calculation of scores}

The values of selected metrics which were attained in the year 2002, 2007 and 2012 are collated and the scores are calculated for each sector according to the adopted scoring methodology. The values and the corresponding scores are consolidated in Table 1 and detailed calculations for some metrics are placed as supplementary material.

\subsection{Calculation of weighting matrix}

The response of seven professionals' working in the energy sector (consultants, analysts, environmentalist, RE entrepreneurs, academicians and demand side experts) was captured separately in a personal (hour long) interview and weights for different metrics for the residential sector and for various dimensions are derived using a process of pair-wise comparison. The theoretical basis and procedure for calculation of weights has been explained in detail in [19].

\subsubsection{Weights for different metrics for residential sector}

The minimum and the maximum weights for different metrics (minimum and maximum values obtained from respondent interviews) are shown in Table 2. The geometric mean of 7 different responses have been used to calculate the consolidated weight of a particular metric.

\subsubsection{Dimensional weights}

Respondents were also interviewed for understanding their perceptions on the relative importance of various dimensions and the weights obtained are summarized in Table 3. For sectors other than residential, only one metric is used for each dimension and hence each metric is allotted the consolidated dimensional weight.

The consolidated weights are then used to fill the weighting matrix and the range of weights is used for undertaking the sensitivity analysis.

\section{Results}

The scoring matrix is multiplied by the weighting matrix to obtain various indices and the weighted scores for different metrics and the SES index for rural/urban areas for the residential sector is shown in Figs. 2a and 2b respectively. The figures represent the performance of the residential sector where 1.0 represents the ideal target which is intended to be achieved.

It is observed that while almost all metrics have shown an increase over time, there is a stark difference between rural and urban areas in the residential sector. The SES index for the residential sector for rural areas in 2012 was 0.53 while that for urban areas was 0.75 . Considering that the residential sector was the largest consumer of energy and accounted for $35.5 \%$ of the share of the total energy consumption in India in 2012, improvement in this sector needs particular attention.

The dimensional indices calculated for different sectors are shown in Figs. 3a-3d. The figures represent the performance of various sectors in different dimensions. It also highlights the comparative performance of various sectors and their performance over the years.

Dimensional indices for different sectors reveal that availability index for residential sector, affordability index for the agricultural sector and acceptability index of the industrial sector is low. Efficiency index of residential, industrial and agricultural sectors also needs large improvements.

The SES index for different sectors and the demand sub-system SES index are shown in Fig. 4. Results reveal that the SES index for the demand sub-system for India has increased by approximately $10 \%$ from 2002 to 2012 . It is also observed that except a drop in the SES index for agriculture sector from 2002 to 2007, all indices have shown an increase from 2002 to 2007 and from 2007 to 2012. This implies that the performance of the energy demand subsystem is showing a gradual improvement and various policies which have been implemented over the last decade have resulted in an increase in SES of the demand sub-system. However, the demand sub-system SES index is approximately 0.7 which is well short of the desired target of 1.0. This implies that there is still a large scope for improvement in the performance of the India's energy demand sub-system.

\section{Discussions}

The dimensional index for availability for the residential sector has increased from 2002 to 2012 due to focused initiatives of the Indian government for provisioning of electricity and LPG in both rural and urban areas. An increase in rural electrification has also lead to a rise in the dimensional index for availability for the agriculture sector. However, for the industrial, transport and services sector there has almost been no change in the availability index.

The dimensional index for affordability for the residential sector has increased from 2002 to 2012 due to a reduction in the distortion of electricity prices. On the other hand, as can be seen from a comparative analysis of various sectors, the performance of the agricultural sector is the poorest due to the high subsidies granted for electricity. For the industrial and the services sector there has almost been no change in the dimensional index for affordability and these sectors continue to cross subsidize electricity to the agriculture and domestic sector. On the other hand there has been a 
Table 1

Actual values and scores for different metrics.

\begin{tabular}{|c|c|c|c|c|c|c|c|c|c|c|}
\hline \multirow[t]{2}{*}{ Dimension } & \multirow[t]{2}{*}{ Sub-component } & \multirow[t]{2}{*}{ Metric } & \multirow[t]{2}{*}{ Target } & \multirow[t]{2}{*}{ Unit } & \multicolumn{3}{|l|}{ Value } & \multicolumn{3}{|l|}{ Score } \\
\hline & & & & & 2002 & 2007 & 2012 & 2002 & 2007 & 2012 \\
\hline \multicolumn{11}{|c|}{ Residential sector } \\
\hline \multirow[t]{8}{*}{ Availability } & Rural & $\mathrm{R} 1$ & 260 & $\mathrm{~kW}$ h/cap/yr & 84.6 & 84.6 & 107.08 & 0.16 & 0.16 & 0.26 \\
\hline & & $\mathrm{R} 2$ & 24 & $\mathrm{~kg} / \mathrm{cap} / \mathrm{yr}$ & 2.88 & 2.88 & 4.55 & 0.00 & 0.00 & 0.00 \\
\hline & & R3 & 100 & $\%$ & 43.5 & 60.2 & 55.3 & 0.29 & 0.50 & 0.44 \\
\hline & & $\mathrm{R} 4$ & 100 & $\%$ & 5.7 & 9.1 & 11.4 & 0.00 & 0.00 & 0.00 \\
\hline & Urban & $\mathrm{R} 1$ & 600 & $\mathrm{~kW}$ h/cap/yr & 267.84 & 267.84 & 310.05 & 0.31 & 0.31 & 0.40 \\
\hline & & $\mathrm{R} 2$ & 24 & $\mathrm{~kg} / \mathrm{cap} / \mathrm{yr}$ & 21.72 & 21.72 & 23.11 & 0.88 & 0.88 & 0.95 \\
\hline & & R3 & 100 & $\%$ & 87.6 & 93.8 & 92.7 & 0.85 & 0.92 & 0.91 \\
\hline & & $\mathrm{R} 4$ & 100 & $\%$ & 48 & 61.8 & 65 & 0.35 & 0.52 & 0.56 \\
\hline \multirow[t]{6}{*}{ Affordability } & Rural & R5 & 7 & $\%$ & 8.80 & 9.72 & 9.24 & 0.45 & 0.90 & 0.92 \\
\hline & & R6 & 1 & - & 0.98 & 0.96 & 0.94 & 0.98 & 0.96 & 0.94 \\
\hline & & R7 & 1 & - & 0.62 & 0.49 & 0.52 & 0.62 & 0.49 & 0.52 \\
\hline & Urban & R5 & 7 & $\%$ & 8.94 & 8.54 & 7.6 & 0.93 & 0.95 & 0.98 \\
\hline & & R6 & 1 & - & 0.78 & 0.68 & 0.65 & 0.78 & 0.68 & 0.65 \\
\hline & & $\mathrm{R} 7$ & 1 & - & 0.57 & 0.58 & 0.63 & 0.57 & 0.58 & 0.63 \\
\hline Acceptability & & R8 & 0.255 & $\mathrm{tCO}_{2} /$ household/yr & 0.33 & 0.35 & 0.30 & 0.93 & 0.91 & 0.96 \\
\hline \multirow[t]{6}{*}{ Efficiency } & Rural & R9 & 30 & $\mathrm{~lm} / \mathrm{W}$ & 6.62 & 9.09 & 8.36 & 0.03 & 0.13 & 0.10 \\
\hline & & R10 & $60 \%$ & $\%$ & 0.18 & 0.21 & 0.20 & 0.12 & 0.18 & 0.18 \\
\hline & & R11 & 1 & - & 0.23 & 0.34 & 0.46 & 0.23 & 0.34 & 0.46 \\
\hline & Urban & R9 & 30 & $\operatorname{lm} / \mathrm{W}$ & 13.16 & 14.08 & 13.92 & 0.30 & 0.34 & 0.33 \\
\hline & & R10 & $60 \%$ & $\%$ & $42.02 \%$ & $48.01 \%$ & $48.18 \%$ & 0.63 & 0.75 & 0.75 \\
\hline & & $\mathrm{R} 11$ & 1 & - & 0.23 & 0.34 & 0.46 & 0.23 & 0.34 & 0.46 \\
\hline \multicolumn{11}{|l|}{ Industry sector } \\
\hline Availability & NA & $\mathrm{I} 1$ & 24 & $\mathrm{Hrs}$ & 22.6 & 22.2 & 22.4 & 0.93 & 0.91 & 0.92 \\
\hline Affordability & & $\mathrm{I} 2$ & 1 & - & 0.99 & 0.98 & 0.98 & 0.99 & 0.98 & 0.98 \\
\hline Acceptability & & I3 & 0.12 & $\mathrm{kCO}_{2} / \$ 05 \mathrm{p}$ & 0.48 & 0.46 & 0.51 & 0.25 & 0.29 & 0.19 \\
\hline Efficiency & & I4 & 0.05 & koe/\$05p & 0.2 & 0.16 & 0.17 & 0.25 & 0.45 & 0.40 \\
\hline \multicolumn{11}{|l|}{ Services sector } \\
\hline Availability & NA & S1 & 24 & Hrs & 23.9 & 23.9 & 23.9 & 1.00 & 0.99 & 0.99 \\
\hline Affordability & & $\mathrm{S} 2$ & 1 & - & 0.95 & 0.93 & 0.95 & 0.95 & 0.93 & 0.95 \\
\hline Acceptability & & S3 & 0.005 & $\mathrm{kCO}_{2} / \$ 05 \mathrm{p}$ & 0.015 & 0.01 & 0.009 & 0.50 & 0.75 & 0.80 \\
\hline Efficiency & & S4 & 0.009 & koe/\$05p & 0.016 & 0.012 & 0.011 & 0.81 & 0.92 & 0.94 \\
\hline \multicolumn{11}{|c|}{ Agriculture sector } \\
\hline Availability & NA & $\mathrm{A} 1$ & 100 & $\%$ & 75 & $79^{\mathrm{a}}$ & 83 & 0.69 & 0.74 & 0.79 \\
\hline Affordability & & A2 & 1 & - & 0.58 & 0.54 & 0.60 & 0.58 & 0.54 & 0.60 \\
\hline Acceptability & & A3 & 0.011 & $\mathrm{kCO}_{2} / \$ 05 \mathrm{p}$ & 0.025 & 0.029 & 0.029 & 0.68 & 0.59 & 0.59 \\
\hline Efficiency & & A4 & 0.006 & koe/\$05p & 0.022 & 0.023 & 0.018 & 0.33 & 0.29 & 0.50 \\
\hline \multicolumn{11}{|c|}{ Transport sector } \\
\hline Availability & NA & $\mathrm{T} 1$ & 82 & $\%$ & 96.07 & 96.02 & 95.78 & 0.96 & 0.96 & 0.96 \\
\hline Affordability & & $\mathrm{T} 2$ & 1 & - & 0.99 & 0.87 & 0.87 & 0.99 & 0.87 & 0.87 \\
\hline Acceptability & & T3 & 0.02 & $\mathrm{kCO}_{2} / \$ 05 \mathrm{p}$ & 0.05 & 0.04 & 0.042 & 0.63 & 0.75 & 0.73 \\
\hline Efficiency & & $\mathrm{T} 4$ & 0.014 & koe/\$05p & 0.016 & 0.014 & 0.015 & 0.96 & 1.00 & 0.98 \\
\hline
\end{tabular}

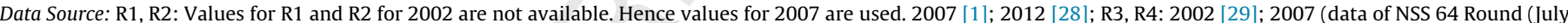

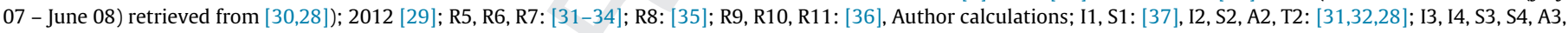
A4, T3, T4: [35]; T1: [38].

a Data is interpolated

Table 2

Weights obtained for different metrics for residential sector.

\begin{tabular}{llclc}
\hline Dimension & Metric & $\begin{array}{l}\text { Min weight } \\
(\%)\end{array}$ & $\begin{array}{l}\text { Max weight } \\
(\%)\end{array}$ & $\begin{array}{l}\text { Consolidated weight } \\
(\%)\end{array}$ \\
\hline Availability & R1 & 8 & 57 & 28.5 \\
& R2 & 10 & 43 & 23.9 \\
& R3 & 11 & 38 & 22.8 \\
& R4 & 6 & 51 & 24.8 \\
Affordability & R5 & 33 & 74 & 62.1 \\
& R6 & 11 & 33 & 18.8 \\
Acceptability & R7 & 9 & 34 & 19.1 \\
Efficiency & R9 & - & - & 100 \\
& R10 & 23 & 65 & 24.4 \\
& R11 & 11 & 65 & 47.6 \\
\hline
\end{tabular}

decrease in the dimensional index for affordability for the transport sector due to an artificial suppression of market prices of pet-

roleum products from 2002 to 2012 .
Table 3

Weights obtained for different dimensions.

\begin{tabular}{llll}
\hline Dimension & Min weight (\%) & Max weight (\%) & Consolidated weight $(\%)$ \\
\hline Availability & 10 & 37 & 27.4 \\
Affordability & 9 & 57 & 26.9 \\
Acceptability & 9 & 51 & 20 \\
Efficiency & 11 & 38 & 25.6 \\
\hline
\end{tabular}

The dimensional index for acceptability for the residential, services and transport sector has increased from 2002 to 2012. This is due to use of cleaner energy sources and lower emissions from the sectors. On the other hand there has been a decrease in the dimensional index for acceptability for the agriculture sector due to higher use of tractors and diesel driven water pumps in the sector. The performance of the industrial sector continues to lag far behind the performance of other sectors in this dimension due to use of polluting fuels such as coal in the sector. 


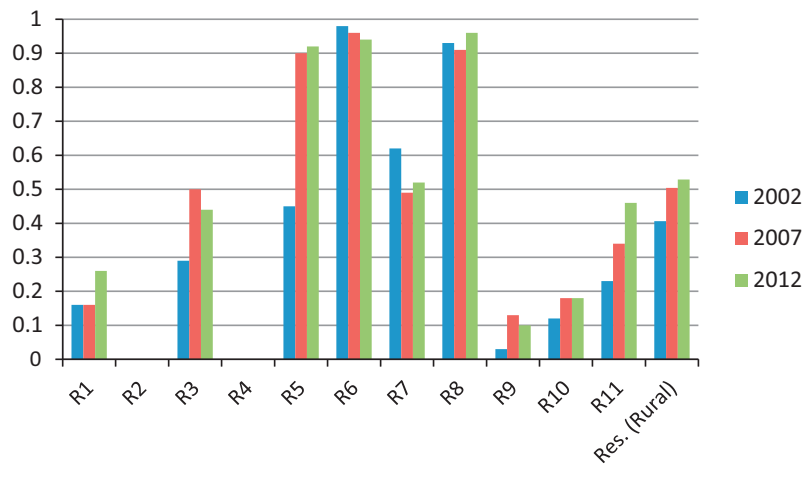

Fig. 2a. Weighted score for metrics and SES index for residential (rural) sector.

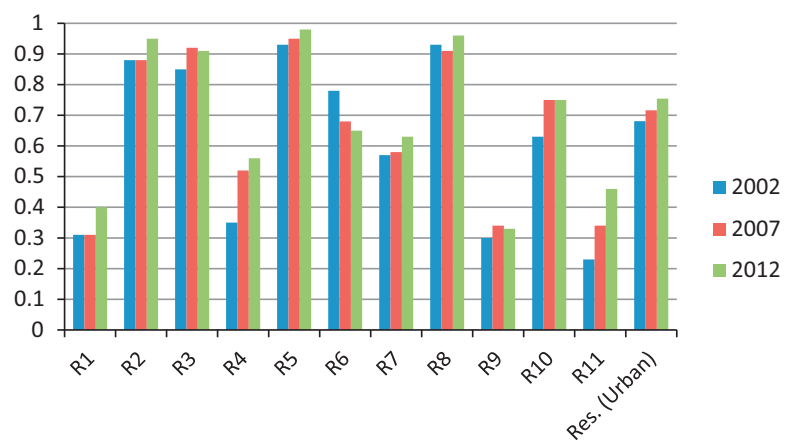

Fig. 2b. Weighted score for metrics and SES index for residential (urban) sector.

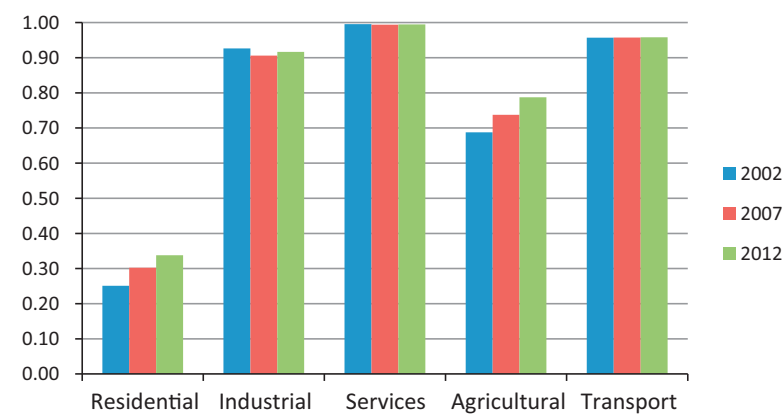

Fig. 3a. Availability index for various sectors.

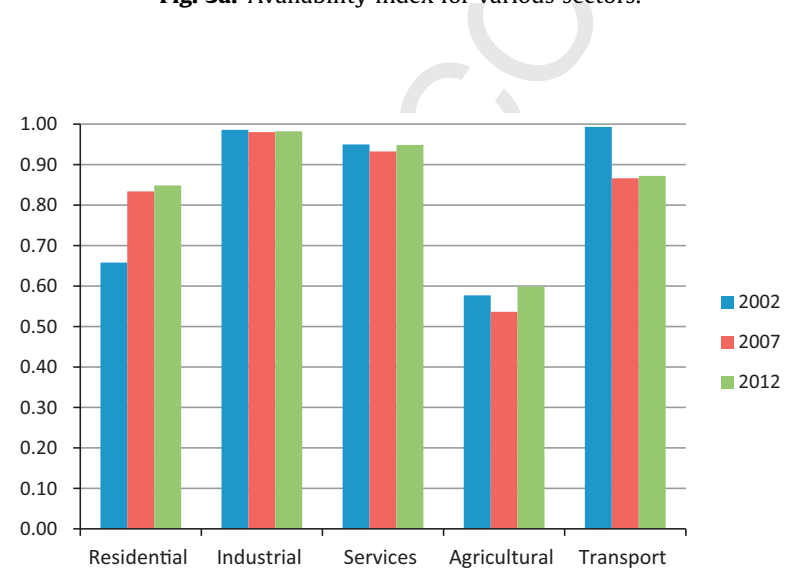

Fig. 3b. Affordability index for various sectors.

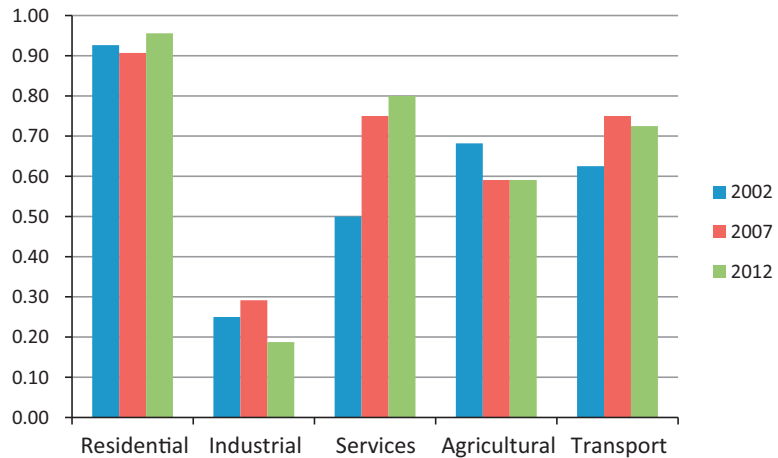

Fig. 3c. Acceptability index for various sectors.

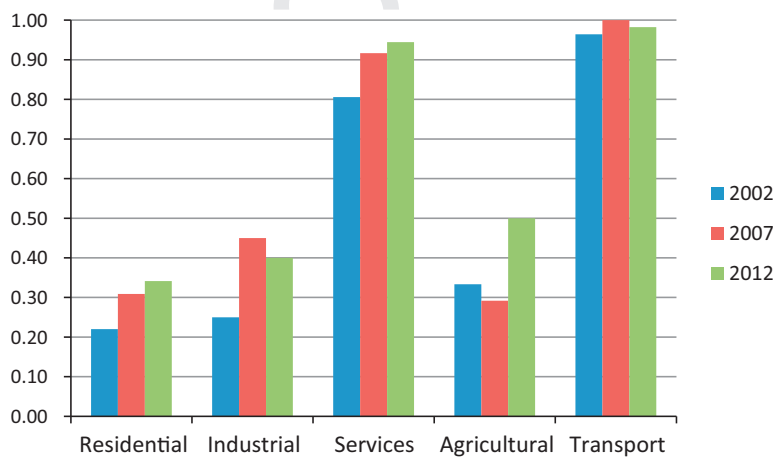

Fig. 3d. Efficiency index for various sectors.

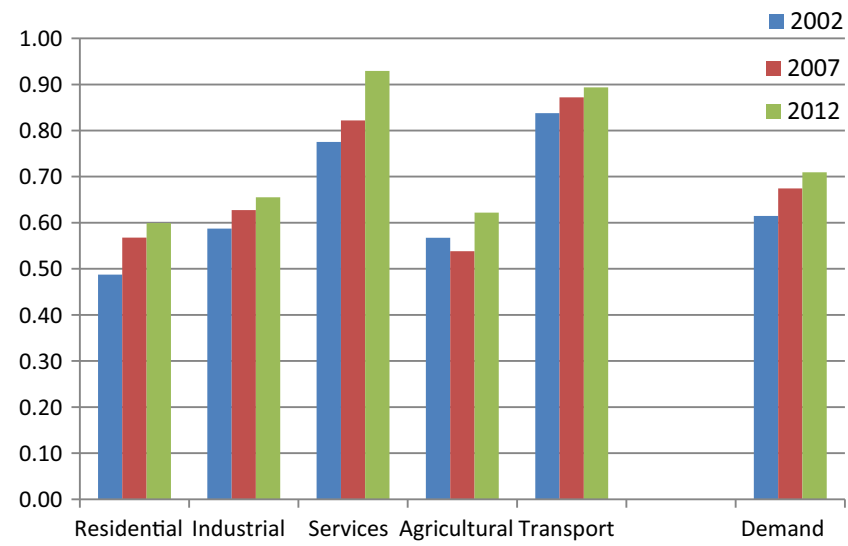

Fig. 4. SES index for different sectors and demand sub-system SES index.

The dimensional index for efficiency for all sectors has shown an improvement due to the focus of the government in promoting energy efficient practices and adoption of energy saving measures by the sectors. A comparative assessment of the sectors however point to the fact that there is still a large scope of improvement in the residential, industrial and the agriculture sectors.

\subsection{Sensitivity to variation in weights}

Twelve scenarios (based on minimum and maximum weights obtained from respondent interview) are created by allotting different weights to metrics of a dimension and the dimensional 
indices are calculated using these scenarios (placed as supplementary material).

\subsubsection{Sensitivity of dimensional indices}

The percentage variation in weights allotted to different metrics by the respondents is shown in Fig. 5a and the sensitivity of dimensional indices to variation in weights allotted to metrics (based on different scenarios) is shown in Fig. 5b respectively. The \% variation is shown as deviation from the consolidated weights (in Fig. 5a) and as a deviation from the dimensional index obtained by using corresponding consolidated weights (in Fig. 5b).

The results of sensitivity to variation in weights can be mathematically analyzed as follows: The set of Eq. (5) shows the calculation of Availability Index (AI) for different scenarios (Sc1-Sc12) for the residential sector.

$$
\begin{aligned}
& \mathrm{AI}(\mathrm{Sc} 1)=w 1 S 1+w 2 S 2+w 3 S 3+(1-w 1-w 2-w 3) S 4 \\
& \cdots \\
& \mathrm{AI}(\mathrm{Sc} 4)=w 1 S 1+(1-w 1-w 3-w 4) S 2+w 3 S 3+w 4 S 4 \\
& \cdots \\
& \cdots \\
& \operatorname{AI}(\operatorname{Sc} 12)=(1-w 2-w 3-w 4) S 1+w 2 S 2+w 3 S 3+w 4 S 4
\end{aligned}
$$

Sc1-Sc12 are different scenarios;

$w 1-w 4$ are different weights for metrics R1-R4; and S1-S4 are scores for metrics R1-R4.

As the sensitivity of AI to weights is to be analysed, a partial derivative of AI with respect to different weights is undertaken and is shown in Eq. (6).

$$
\begin{aligned}
& \frac{\partial \mathrm{AI}(\mathrm{Sc} 1)}{\partial w 1}=S 1-S 4 \\
& \frac{\partial \mathrm{AI}(\mathrm{Sc} 2)}{\partial w 1}=S 1-S 3 \\
& \frac{\partial \mathrm{AI}(\mathrm{Sc} 4)}{\partial w 1}=S 1-S 2 \\
& \frac{\partial \mathrm{AI}(\mathrm{Sc} 10)}{\partial w 1}=0
\end{aligned}
$$

Similarly, partial derivatives of AI with respect to $w 2, w 3$ and $w 4$ will yield $\left(S_{x}-S_{y}\right)$, where $x, y$ vary between 1 and 4 . Eq. (6) shows the calculation of percentage variation of the AI.

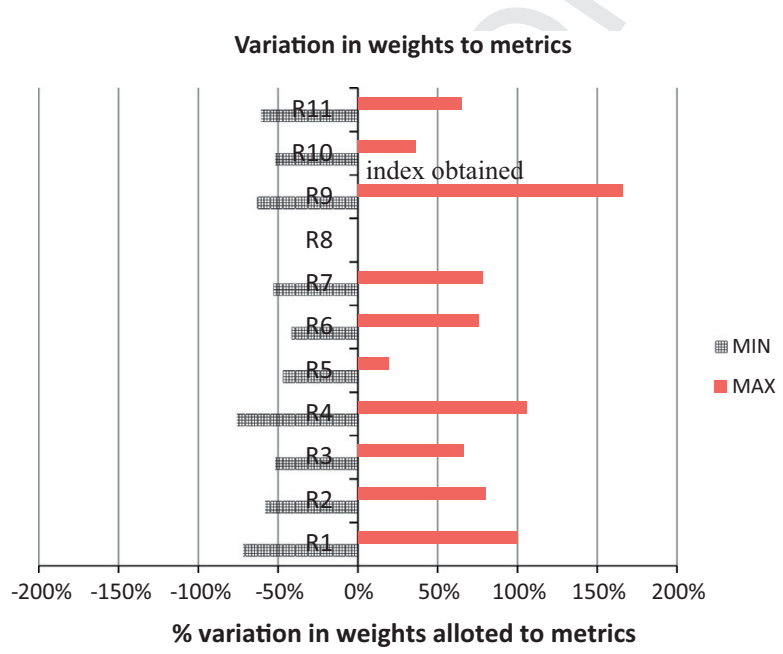

Fig. 5a. Variation in weights allotted to different metrics.

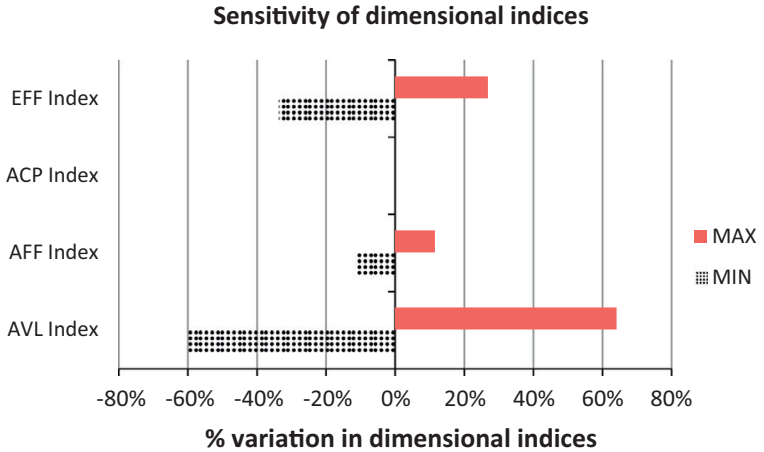

Fig. 5b. Sensitivity of dimensional indices to variation in metric weights.

$\%$ variation $(\mathrm{AI})=\frac{\mathrm{AI}\left(\mathrm{Sc}_{x}\right)-\mathrm{AI}(\text { Consolidated })}{\mathrm{AI}(\text { Consolidated })} * 100$

where

$\mathrm{Sc}_{x}$ are various scenarios $(x=1-12)$

$\mathrm{AI}\left(\mathrm{Sc}_{x}\right)$ is the AI calculated for different scenarios; and

AI (Consolidated) is the AI calculated using consolidated weights.

Drawing inferences from Eq. (7), it can be concluded that the sensitivity of the dimensional index to weights is directly proportional to the differential between the scores of the metrics and is inversely proportional to the value of the dimensional index calculated using consolidated weights. It can therefore be concluded that while different weights allotted to different metrics will yield different dimensional indices, the dimensional indices are more sensitive to variation in weights if the range of scores for metrics for a particular dimension, is large. Secondly, a lower absolute value of the dimensional index (due to low scores of various metrics) leads to higher sensitivity of the dimensional index. Hence if a particular dimension has unbalanced and low scores, the sensitivity of that dimensional index to variation in weights allotted to the metric is high.

\subsubsection{Variation in weights of dimensions}

The four dimensions and 12 scenarios are created by allotting different sets of weights to different dimensions. The range of weights and the variation in SES index for the demand subsystem (for the year 2012) are shown in Fig. 6.

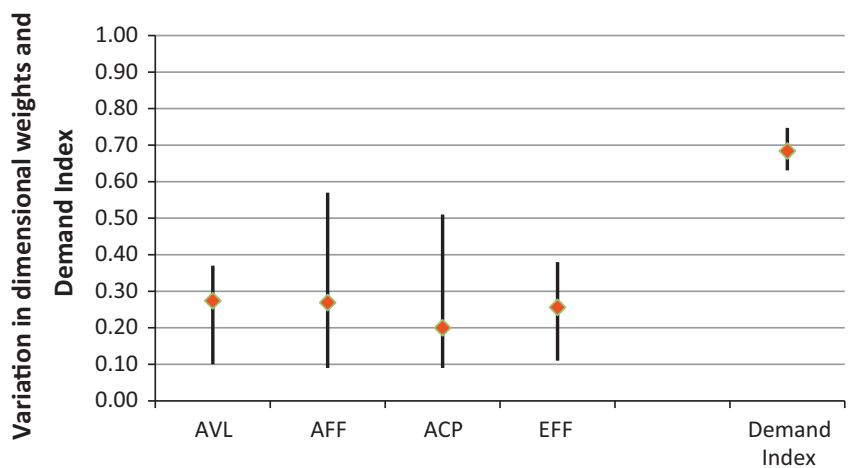

Fig. 6. Variation in dimensional weights and demand index. 
Table 4

Comparison of scores using different scoring rules.

\begin{tabular}{|c|c|c|c|c|c|}
\hline \multicolumn{3}{|c|}{ Lower values } & \multicolumn{3}{|c|}{ Higher values } \\
\hline$X$ (Target) & Org. Score & New Score & $X$ (Target) & Org. Score & New Score \\
\hline 0.5 & 1 & 1 & 0.0 & 0 & 0 \\
\hline 1.0 & 1 & 1 & 0.2 & 0 & 0 \\
\hline 1.5 & 0.875 & 0.5 & 0.4 & 0.25 & 0 \\
\hline 2.0 & 0.75 & 0 & 0.6 & 0.5 & 0.2 \\
\hline 3.0 & 0.5 & 0 & 0.8 & 0.75 & 0.6 \\
\hline 5.0 & 0 & 0 & 1 & 1.0 & 1.0 \\
\hline
\end{tabular}

The results show that despite the large variation in dimensional weights ( $-67 \%$ to $+155 \%$ from the consolidated weights), the percentage change in the demand index is within \pm 10 percent (when consolidated weights are used). This implies that the demand subsystem SES index is relatively robust to variation in weights allotted to different dimensions.

\subsection{Sensitivity of SES index to variation in scoring rules and to threshold values}

For the current assessment the scoring rules shown in Eqs. (2) and (3) are used. Suppose the value of ' $f$ is assumed as (1/2) instead of (1/5), Eqs. (2) and (3) will now be modified as shown in Eqs. (8) and (9):

(a) For metrics where lower values are desirable

If value $(x) \leqslant \operatorname{target}(x):$ Score $=1$

If $2 *$ target $(x)>$ value $(x)>\operatorname{target}(x)$ : Score

$$
=\left(\frac{(2 * \text { target }-x)}{1 * \text { target }}\right)
$$

If value $(x) \geqslant 2 *$ target $(x)$ : Score $=0$

(b) For metrics where higher values are desirable

If value $(x) \geqslant \operatorname{target}(x):$ Score $=1$

If $0.5 *$ target $(x)<$ value $(x)<\operatorname{target}(x)$ : Score

$$
=\left(\frac{x-(\text { target } / 2)}{\left(\frac{1}{2}\right) * \text { target }}\right)
$$

If value $(x) \leqslant 0.5 *$ target $(x):$ Score $=0$

Comparisons of original and new scores for metrics where the desired values are lower or higher are shown in Table 4. It is observed from Table 4 that the score obtained for a particular value of $x$ using the new scoring rules is lower than the original score. While this would lower the absolute value of each dimensional index, SES index for the sector and sub-system SES index, this effect will be uniform across all time periods. The scoring rules therefore do not change the results when used for comparison across various years for a particular country. Similarly, a change in the target value for each metric uniformly affects the scores of different metrics across all periods and hence does not dilute the usefulness of the indices for measuring the SES index over time.
However, the choice of scoring rules does affect the results in a different way. While the scores obtained from the old and the new scoring rules continue to lie between 0 and 1 , the range of input values, which yield a non-zero score, is compressed. Hence using the new scoring rules would lead to a lower resolution in the index and the information of the actual value of the metric may get lost. The scoring rule given in Eqs. (2) and (3) is therefore preferred and is used for the assessment.

\section{Conclusion}

This paper has undertaken an assessment of the SES for the energy demand sub-system for India. The dimensional and sectoral indices have been calculated for different years and the SES index for the demand sub-system has been aggregated. This quantitative assessment reveals key characteristics of the performance of the Indian energy demand sub-system over time. Results illustrate that almost all indices show an improvement from 2002 to 2012 and the overall SES index for the demand sub-system has shown a gradual increase over the years. Nevertheless, there is a large scope for improvement as the overall SES index for the demand subsystem is about $70 \%$ of the targeted value. The SES for the residential sector in rural areas is relatively much lower than those in urban areas and specific policies have to be implemented for providing clean and affordable energy in rural areas. Sensitivity analysis reveals that the SES index is robust to variation in weights and the results of the SES index can be used with reasonable confidence.

The results of the SES index for different sectors reveal a clear trend in the improvement of the performance of the sectors from 2002 to 2012. The absolute values of the index indicate that there is further scope of their improvement as they fall short of the ideal index of 1.0. The comparative assessment reveals that the performance of the agricultural sector is the weakest while that of the services sector is the strongest. However it is recommended that for an indepth assessment of the sector, an analysis of individual metrics has to be undertaken.

The methodology incorporates sufficient flexibility in its approach and the researcher can select different metrics based on their applicability to a country. As the weights are derived based on an interview, the perception of respondents is captured in the assessment and reflects the concerns on energy security and sustainability for the country. Such a comprehensive assessment for India has not been attempted to date. Due to the above mentioned reasons, the assessment of the demand sub-system gives new insights which can be used to design policy interventions for improving the overall SES index for India.

\section{Uncited references}

$$
\text { [39-43]. }
$$

\section{Acknowledgements}

The authors are grateful to the following individuals for their time and for providing their responses based on which weights were derived: Ajit Panda, Amit Bhandari, Balwant Joshi, Shireesh Kedare, Siddharth AS and Sudhakar Yedla. 


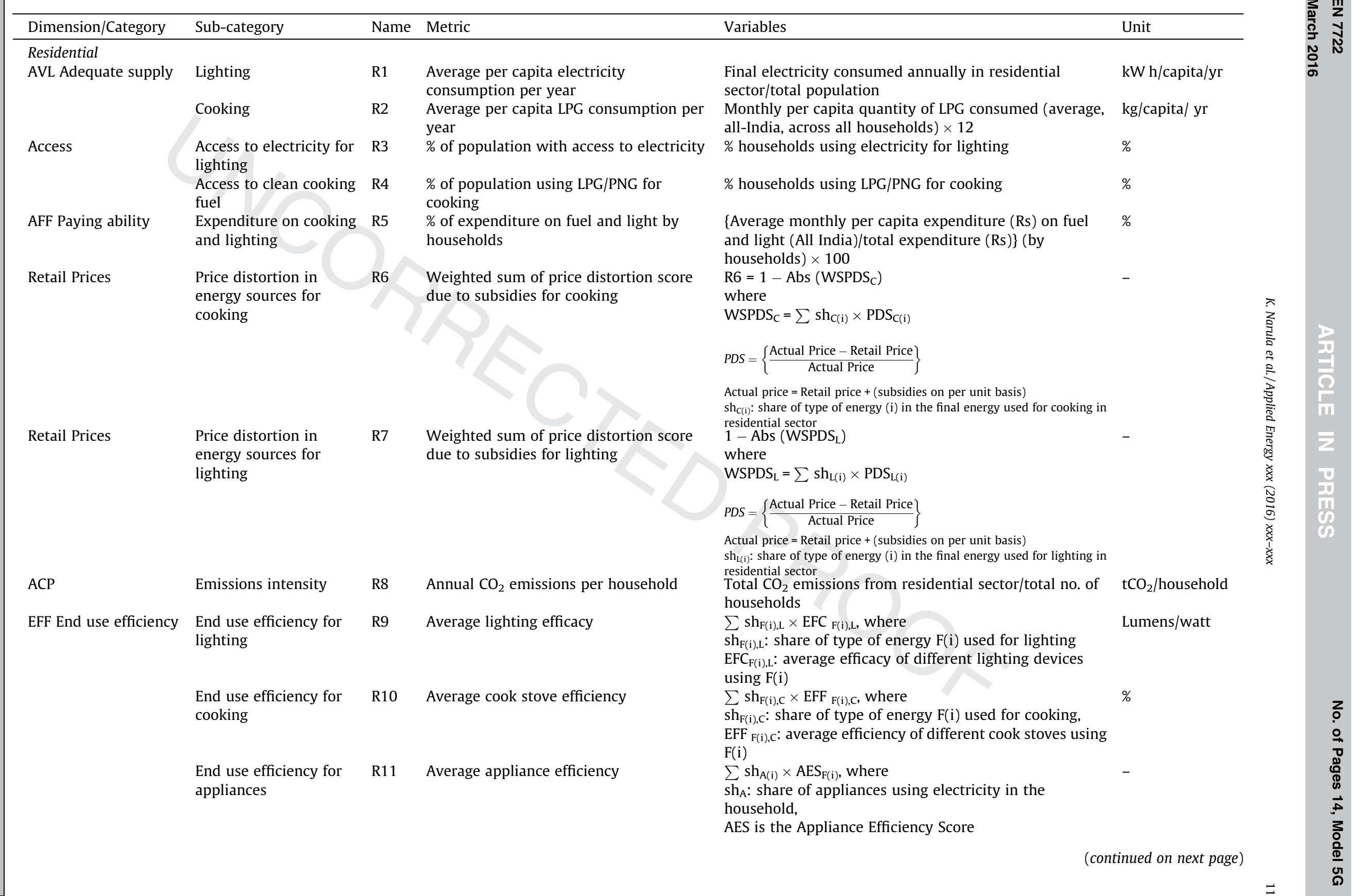




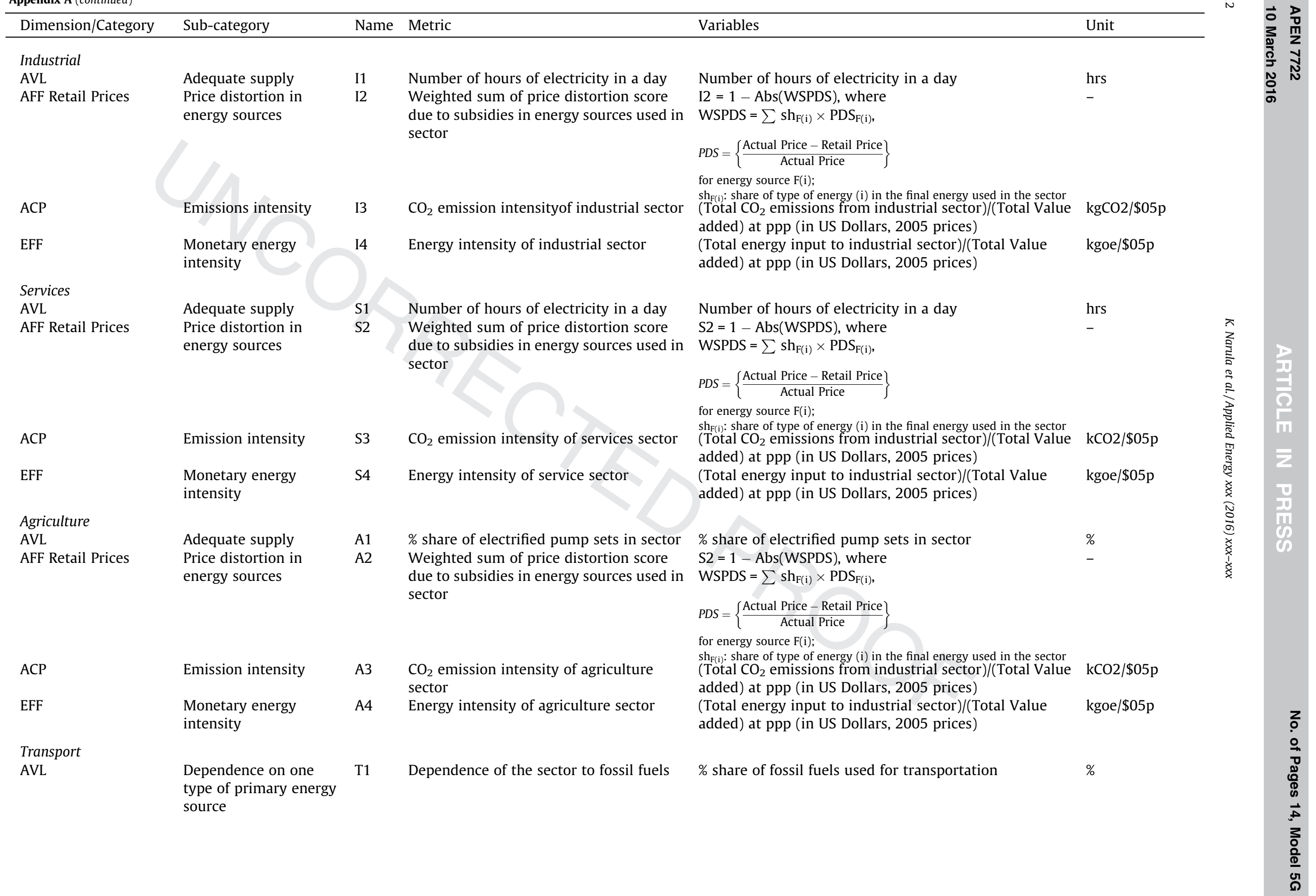




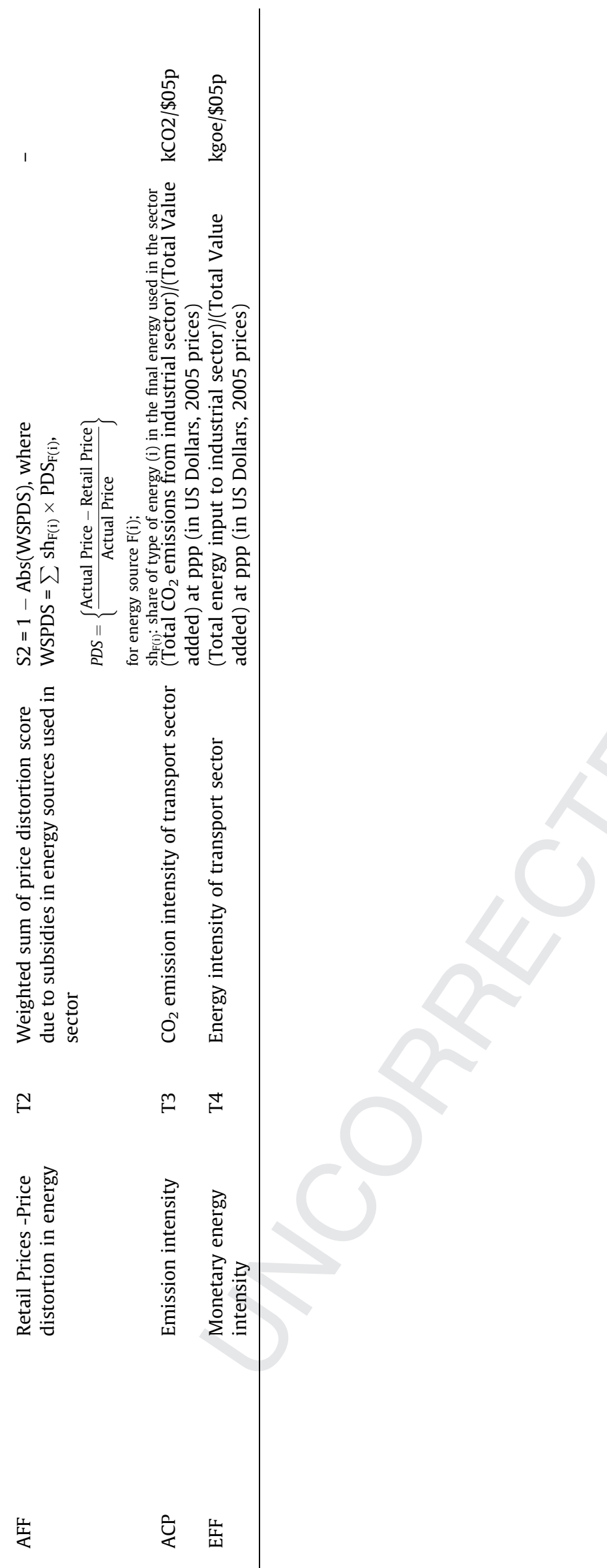

\section{Appendix B. Supplementary material}

Supplementary data associated with this article can be found, in the online version, at http://dx.doi.org/10.1016/j.apenergy.2016. 02.142 .

\section{References}

[1] Narula K. Is sustainable energy security of India increasing or decreasing? Int J Sustain Energ 2014;33(6):1054-75.

[2] Mitchell C, Watson J. Introduction: conceptualizing energy security. In: Mitchell C, Watson J, Whiting J, editors. New challenges in energy security: the UK in a multipolar world. Basingstoke: Palgrave MacMillan; 2013. p. 238-57.

[3] Hughes L. A generic framework for the description and analysis of energy security in an energy system. Energy Policy 2012;42:221-31.

[4] Narula K, Reddy B. A SES (sustainable energy security) index for developing countries. Energy 2016;94:326-43.

[5] Planning Commission. Integrated energy policy: report of the expert committee. New Delhi: Government of India; 2006.

[6] Narula K, Reddy B. Three blind men and an elephant: the case of energy indices to measure energy security and energy sustainability. Energy 2015;80:148-58.

[7] Coude J. Literature review on energy efficiency and energy security, including power reliability and avoided capacity costs. Antwerp. <http://combi-project. eu/wp-content/uploads/2015/09/D7.1.pdf>; 2015.

[8] Gupta E. Oil vulnerability index of oil-importing countries. Energy Policy 2008;36(3):1195-211.

[9] Cabalu H. Indicators of security of natural gas supply in Asia. Energy Policy 2010;38:218-25.

[10] Cohen G, Joutz F, Loungani P. Measuring energy security: trends in the diversification of oil and natural gas supplies. Energy Policy 2011;39:4860-9.

[11] Le Coq C, Paltseva E. Measuring the security of external energy supply in the European Union. Energy Policy 2009;37(11):4474-81.

[12] Jewell J. The IEA model of short-term energy security (MOSES). Paris: OECD Publishing; 2011.

[13] Ang B, Choong W, Ng T. A framework for evaluating Singapore's energy security. Appl Energy 2015;148:314-25.

[14] Phdungsilp A. Assessing energy security performance in Thailand under different scenarios and policy implications. Energy Procedia 2015;79:982-7.

[15] Tongsopit S, Kittner N, Chang Y, Aksornkij A, Wangjiraniran W. Energy security in ASEAN: a quantitative approach for sustainable energy policy. Energy policy 2016;90:60-72.

[16] Kucharski J, Unesaki H. A policy-oriented approach to energy security. Procedia Environ Sci 2015;28:27-36.

[17] Seebregts AJ, De Jong JJ, Maters JM. EU standards for energy security of supply. ECN; 2006.

[18] Scheepers M, Seebregts A, de Jong J, Maters H. EU standards for energy security of supply. Gas 2007;52(6).

[19] Narula K. Comparative assessment of energy sources for attaining Sustainable Energy Security (SES): the case of India's residential sector. Int J Sustain Energy Plann Manage 2015;5:27-40.

[20] SE4ALL. Sustainable Energy for All (SE4All). <http://www.se4all.org/ourvision_our-objectives>; 2012 [accessed 26.01.16].

[21] European Commission. Europe 2020 - EU-wide headline targets for economic growth - European Commission. <http://ec.europa.eu/europe2020/targets/eutargets/index_en.htm>; 2011 [accessed 26.01.16].

[22] Congressional Research Service. China's greenhouse gas emissions and mitigation policies. Washington D.C.: CRS; 2011.

[23] Hurst N. An assessment of India's 2020 carbon intensity target. London: Grantham Institute for Climate Change; 2012.

[24] De la Rue du Can S, Letschert V, Mc Neil M, Zhou N, Sathaye J. Residential and transport energy use in India: past trend and future outlook, Lawrence Berkeley National Laboratory. Oak Ridge: Environmental Energy Technologies Division; 2009.

[25] The World Bank. Residential consumption of electricity in India. <http:// www.moef.nic.in/downloads/public-information/ Residentialpowerconsumption.pdf; 2008 [accessed 15.04.15].

[26] D'sa A, Murthy KN. Report on the use of LPG as a domestic cooking fuel option in India. Int Energy Initiative 2004;Bangalore:17-9.

[27] Chunekar A, Kadav K, Singh D, Sant G. Potential savings from selected superefficient electric appliances in India. Pune: Prayas Energy Group; 2011.

[28] NSSO (National Sample Survey Organisation). Household consumer expenditure in India, 2007-08 [Report No. 530], NSS 64th round (July 2007 - June 2008). Ministry of Statistics and Programme Implementation. New Delhi: Government of India; 2010.

[29] NSSO (National Sample Survey Organisation). Household consumption of various goods and services in India, 2011-12 [Report No. 558], NSS 68th round (July 2011 - June 2012). Ministry of Statistics and Programme Implementation. New Delhi: Government of India; 2014.

[30] Registrar General, I. Census of India 2011.Office of the Registrar General Census Commissioner, India. Indian Census Bureau; 2011.

[31] Harish SM, Tongia R. Do rural residential electricity consumers cross-subside their urban counterparts? Exploring the inequity in supply in the Indian power sector; 2014. 
[32] NSSO (National Sample Survey Organisation). Household consumer expenditure and employment - unemployment situation in India, 2001 2002 [Report No. 481]. NSS 57th Round (July 2001 - June 2002). Ministry of Statistics and Programme Implementation. New Delhi: Government of India; 2003.

[33] NSSO (National Sample Survey Organisation). Energy sources of Indian households for cooking and lighting, [Report No. 542], NSS 66th round (July 2009 - June 2010). Ministry of Statistics and Programme Implementation. New Delhi: Government of India; 2012.

[34] NSSO. Household consumption of various goods and services in India, [Report No. 541], NSS 66th round (July 2009 - June 2010). National Sample Survey Office, Ministry of Statistics and Programme Implementation. New Delhi: Government of India; 2012.

[35] TERI (The Energy and Resources Institute). TERI energy data directory \& yearbook, 2010. New Delhi: Energy and Resources Institute; 2011.

[36] Ministry of Petroleum \& Natural Gas. Indian Petroleum \& Natural Gas Statistics (2011-12), Economic Division, Ministry of Petroleum \& Natural Gas. New Delhi: Government of India; 2013. p. 61-4.
[37] IEA (International Energy Agency). World Energy Balance - Sankey Diagram. [Data File]. <http://www.iea.org/sankey/>; 2015.

[38] WEC (World Energy Council). Energy efficiency indicators (Data provided by Enerdata); 2015.

[39] PPAC (Petroleum Planning \& Analysis Cell). Ministry of petroleum \& natura gas. New Delhi: Government of India; 2015.

[40] Planning Commission Annual Report (2001-02) on the Working of State Electricity Boards \& Electricity Departments. Power \& Energy Division, Planning Commission. New Delhi: Government of India; 2002.

[41] Planning Commission. Annual Report 2011-12 on the Working of State Power Utilities \& Electricity Departments. Power \& Energy Division, Planning Commission. New Delhi: Government of India; 2011.

[42] Ravindranath NH, Ramakrishna J. Energy options for cooking in India. Energy Policy 1997;25(1):63-75.

[43] CEA (Central Electricity Authority). Report on 18th Electric Power Survey of India. New Delhi: Govt. of India, Ministry of Power, Central Electricity Authority; 2013. 